Review Article

\title{
WOUND HEALING CONCEPTS: CONTEMPORARY PRACTICES AND FUTURE PERSPECTIVES
}

\author{
SHARON C. FURTADO*, BHARATH SRINIVASAN, SINDHU ABRAHAM
}

Department of Pharmaceutics, Faculty of Pharmacy, M. S. Ramaiah University of Applied Sciences, Gnanagangothri Campus, Bengaluru 560054, Karnataka, India

Email: sharoncaroline.ps.ph@msruas.ac.in

Received: 02 Jun 2020, Revised and Accepted: 21 Jul 2020

\section{ABSTRACT}

The advancements in the development of wound dressings have seen tremendous growth in the past few decades. Wound healing approach has majorly shifted from dry healing to moist healing. There has been a significant advancement in our understanding of the underlying physiology involved in wound healing and the associated systemic factors having a direct or indirect influence on the healing. This has resulted in the development of wound dressings designed to treat specific types of wounds. The present review discusses the physiology of wound healing, followed by different factors that contribute to healing. The advancements in wound dressings with their merits and limitations, newer approaches in wound care i.e., hyperbaric oxygen, negative pressure therapy, skin substitutes and role of growth factors in wound healing, have been highlighted. In addition, more recent approaches for effective wound care like smart devices with sensing, reporting and responding functions are discussed.

Keywords: Wound healing, Moist healing, Skin substitute, Negative pressure therapy

(c) 2020 The Authors. Published by Innovare Academic Sciences Pvt Ltd. This is an open access article under the CC BY license (http://creativecommons.org/licenses/by/4.0/) DOI: http://dx.doi.org/10.22159/ijap.2020v12i5.38588. Journal homepage: https://innovareacademics.in/journals/index.php/ijap

\section{INTRODUCTION}

The skin is an intricate structure composed of the epidermis and dermis, including the subcutaneous fat or dermal adipocyte layer. The skin also protects the underlying organs, a function necessary for the survival of the organism [1]. The epidermis consists of keratinocytes and it protects the body from the outside environment. The dermis consists of collagen fiber, blood vessels, sweat glands, and hair. Subcutaneous fat stores nutrients and prevents heat from escaping the body [2] (fig. 1).

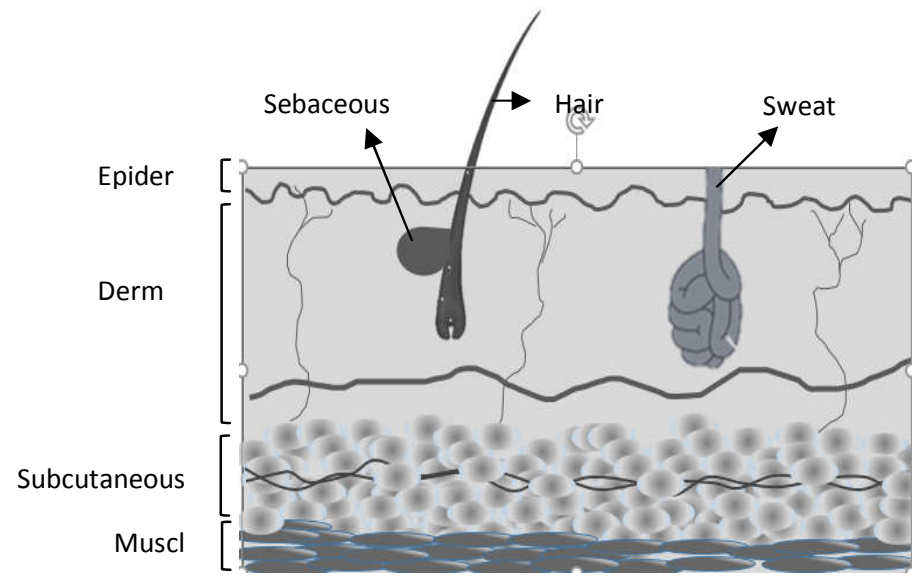

Fig. 1: Structure of skin

\section{Skin wounds}

Skin wounds are the result of the disruption of the normal anatomic structure of skin hence affecting their function [3]. A wound can be described as a defect or a break in the skin, resulting from physical or thermal damage or because of the presence of an underlying medical or physiological condition [4]. Wounds can be classified on the basis of nature of healing process, the number of skin layers and area of skin infected.

Based on the nature of healing process, wounds are classified as acute and chronic. Acute wounds are mainly caused due to superficial mechanical injuries like friction and abrasion. Clean penetrating wounds caused by knives or surgical incisions and superficial burn wounds can also be classed as acute. These tissue injuries heal completely, with minimal scarring, within the expected time frame, usually 8-12 w without complications. Chronic wounds are a result of tissue injuries that heal slowly, generally healing period prolonged beyond $12 \mathrm{w}$. These wounds if not healed completely also have issues of recurrence. The non-healing nature of such wounds is usually due to underlying physiological conditions like diabetes, deficiencies, malignancies, persistent infections and other patient-related factors $[2,4]$

Wounds are also classified based on the number of skin layers and the area of skin affected. Superficial wounds are injuries affecting only the epidermal layer. Injuries affecting deeper dermal layers, including blood vessels, sweat glands and hair follicles are referred to as partial-thickness wounds. Full-thickness wounds are those affecting underlying subcutaneous fat or deeper tissues in addition to the epidermis and dermal layers [4].

\section{Wound healing}

Wound healing is a highly complex physiological process involving the involvement of various cells and biochemical components. The 
entire healing process is accompanied by activation of severa enzymatic pathways which ultimately help the tissue to heal [5]. The process involves regeneration and replacement of damaged tissues. The healing progresses through a series of interdependent and overlapping phases that help in replacement of lost tissue and re-establishment of tissue integrity. The different stages involved in wound healing are hemostasis, inflammation, migration, proliferation and maturation phase $[3,5,7]$. The events occurring during these phases are depicted in fig. 2 .

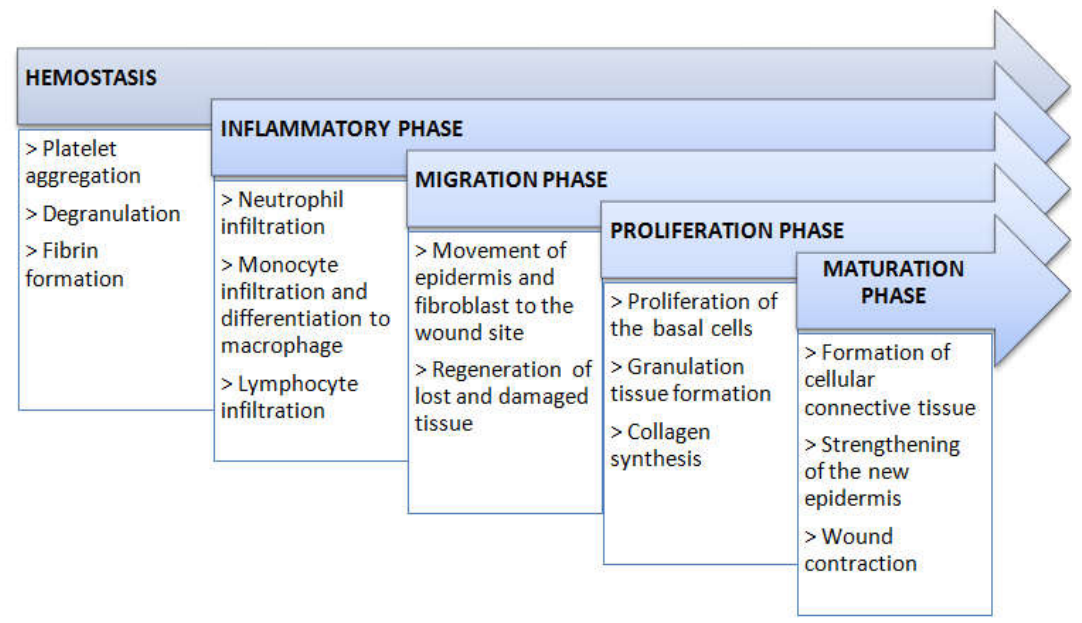

Fig. 2: Different stages of wound healing

\section{Factors affecting wound healing}

Factors affecting wound healing can be categorized as local and systemic. Factors that have a direct influence on the healing of the wound are classified as local factors. Other factors that are not directly located at the wound site but have an influence on the healing are classified under systemic factors $[6,8,9]$. The local and systemic factors affecting wound healing are summarized in table 1

Table 1: Local and systemic factors affecting wound healing

\begin{tabular}{lc}
\hline Factors affecting wound healing & References \\
\hline Local & {$[10-13]$} \\
Oxygenation & {$[14-16]$} \\
Infection & {$[18-19]$} \\
Maceration & {$[20]$} \\
Necrosis & {$[21]$} \\
Trauma & {$[21]$} \\
Oedema & {$[22,23]$} \\
Desiccation & {$[24-26]$} \\
Systemic & {$[27,28-31]$} \\
Age & {$[32]$} \\
Stress & {$[33]$} \\
Dischemia & {$[35]$} \\
Obesity & {$[36]$} \\
Medications: glucocorticoid steroids, NSAID's & {$[46-49]$} \\
Alcoholism and smoking & {$[9,50]$} \\
\hline
\end{tabular}

\section{Local factors}

\section{Oxygenation}

Oxygen is critical for all stages of wound healing. Healing tissue also has an increased energy demand. The mitochondrial enzyme cytochrome oxidase requires oxygen for energy metabolism i.e. production of high-energy phosphates for various cellular functions. The process of collagen synthesis involves the production of procollagen, followed by collagen maturation. Oxygen is involved in the hydroxylation of proline and lysine into procollagen. The phase of angiogenesis is initiated by hypoxia. But reports suggest that the administration of oxygen can accelerate and sustain the growth of blood vessels. Oxygen also exhibits antimicrobial activity. Leukocytic $\mathrm{NADPH}$ oxidase converts oxygen to a superoxide ion which kills bacteria [10-13]. Overall, the effects of oxygenation on tissue healing are summarised in fig. 3 .

\section{Infection}

Based on the state of replication of microorganisms, wound infections can be classified as:

$>$ Contaminated-presence of non-replicating organisms on a wound

$>$ Colonization-the presence of replicating microorganisms on the wound without tissue damage

$>$ Local infection/critical colonization-microorganism replication and the beginning of local tissue responses

$>$ Spreading invasive infection-the presence of replicating organisms within a wound with subsequent host injury [14-16].

Inadequate control measures to manage infected wounds can lead to cellulitis (cell inflammation) and, ultimately, bacteremia and 
septicemia, both of which can be fatal. Bacteria and endotoxins can lead to the elevation of pro-inflammatory cytokines such as interleukin-1 (IL-1) and TNF- $\alpha$ both of which are known to elongate the inflammatory phase. Prolonged inflammation leads to an increased level of matrix metalloproteases (MMPs), a family of proteases that can degrade the extracellular matrix. This also causes degradation of growth factors in the wound. As a consequence, the wound may enter a chronic state and fail to heal $[9,17]$.

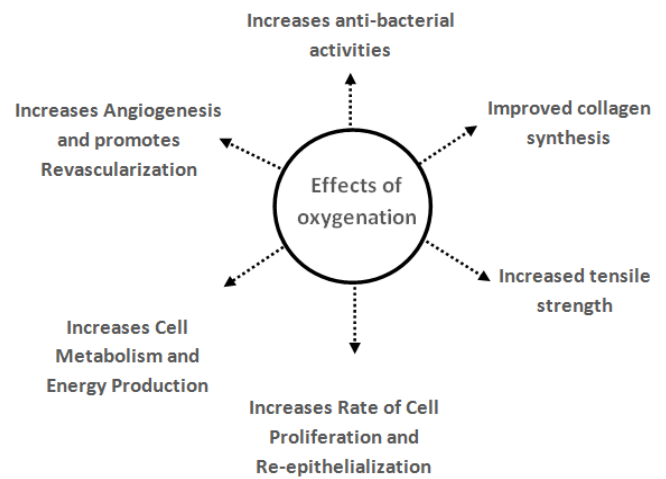

Fig. 3: Effects of oxygenation in tissue healing

\section{Maceration}

Maceration of the epithelium has been described as the softening of the skin by prolonged exposure to excessive amounts of liquid. This may be due to excess exudates, sweat accumulation or incontinence. Maceration decreases the physical and chemical integrity of the stratum corneum which acts as a predisposing factor for potential microbial invasion and increased susceptibility to injury by mechanical forces, ultimately leading to enlargement of the wound. Maceration increased susceptibility to mechanical forces and infection $[18,19]$.

\section{Necrosis}

Non-viable, devitalized, necrotic tissue can impede the healing process. This necrotic tissue can also harbor pathogenic microorganisms. The commonly found necrotic tissues that can delay the healing process are slough and eschar. Slough is cream or yellow, loose, moist necrotic tissue and eschar is black, dry, thick, hard and leathery. The two types of necrotic tissue can delay the process of healing. Necrotic tissue needs to be removed by suitable means to facilitate the healing process [20].

\section{Trauma and blood supply}

Wounds that are repeatedly traumatized example, by frequent dressing changes, heal slowly or may not heal at all. Also, wounds that are deprived of local blood supply by edema exhibit impaired healing. An adequate blood supply ensures delivery of nutrients, gas and allows metabolite exchange. This is a requirement for the migration of dermal and epidermal cells within the wound bed [21].

\section{Desiccation}

For optimum healing, wounds should be physiologically moist, not dry and not too wet [22]. Complete removal of moisture from the wound surface removes the physiological fluids that contain chemicals like cytokines and growth factors that support wound healing activity. Dried wounds are more painful, itchy and produce scab material in an attempt to reduce fluid loss. Cell proliferation, leukocyte activity, wound contraction, and revascularization are reduced in a dry environment. Epithelialization is drastically slowed in the presence of scab tissue that forces epithelial cells to burrow rather than freely migrate over granulation tissue [23]

\section{Systemic factors}

\section{Age}

Wound healing is generally delayed in the elderly due to slower metabolism. Also, the healed wounds do not have structural integrity as found in young. The skin in the elderly generally is associated with flattening of the dermal-epidermal junction, the skin is more susceptible to tears and there is a reduction in collagen quality and quantity. The overall immunity is declined making the wounds more vulnerable to microbial contamination.

The factors that complicate the healing process in older patients include nutritional deficiencies, altered hormonal responses, poor hydration, and conditions like diabetes mellitus, heart disease, and peripheral ischemia. All phases of wound healing are compromised, including decreased inflammatory and proliferative responses, delayed angiogenesis, delayed remodeling, and slower re-epithelialization [24-26].

\section{Psychological stress}

Evidence from experimental and clinical models of wound healing indicates that psychological stress leads to clinically relevant delays in wound healing. Stress reduces antimicrobial peptides and also has adverse effects on the immune system. This makes the wounds more susceptible to microbial infection $[27,28]$.

The release of adrenaline during stress causes peripheral vasoconstriction and thus reduces perfusion and delays wound healing. Stress increases levels of glucocorticoids leading to suppression of inflammatory and immune responses. Psychological stress impairs normal cell-mediated immunity at the wound site, causing a significant delay in the healing process [28-31]

\section{Ischemia}

Blood supplies leucocytes, nutrients, oxygen and removes waste products from the wound site. Adequate blood supply keeps the wound warm and promotes wound healing. Molecular oxygen is also essential during collagen synthesis. Hydroxylation of proline and lysine involves the enzyme prolyl hydroxylase, which requires sufficient oxygen supply for adequate functioning. Also, the collagen synthesis by human dermal fibroblasts drops considerably under hypoxic conditions. Oxygen is also crucial for the inflammatory phase of wound healing [32].

\section{Diseases}

Chronic diseases such as anemia, diabetes, chronic obstructive pulmonary disease (COPD), arteriosclerosis, peripheral vascular disease (PVD), heart disease, and any conditions leading to hypotension, hypovolemia, edema, and anemia can compromise wound healing. Chronic circulatory diseases reduce blood flow and hence affect various stages of wound healing. Autoimmune diseases alter the normal immune function. This affects the inflammatory phase that the WBCs coordinate the normal sequence of events in wound healing. Autoimmune diseases such as lupus and rheumatoid arthritis interfere with normal collagen deposition and impair granulation. Diabetes is associated with delayed response to injury and impaired functioning of immune cells. Also seen are defects in collagen synthesis and reduced wound tensile strength after healing [33].

\section{Obesity}

Obesity has both a direct and indirect effect on wound healing. Direct effects include reduced blood supply, protein malnutrition, which impedes healing rates. Indirectly, obesity can be connected to stress, anxiety, and depression, all situations which can cause an impaired immune response. Also, the reduced mobility of overweight individuals can lead to an increased risk of hernia formation and infection [34]. Bone marrow-derived endothelial progenitor cells (EPCs) are responsible for 35\% of new blood vessel formation in healing wounds. There is a hypothesis that dysfunction in EPC can lead to impaired wound healing in obese patients [35].

Medications: glucocorticoid steroids, non-steroidal antiinflammatory drugs

Patients with chronic non-healing wounds are often found with comorbidities and hence polypharmacy is also a common accompanying feature. While some medications like vasodilators are reported to improve wound healing in certain cases, many others like corticosteroids, NSAID's, antihistamines, etc. are reported to significantly delay the process of healing or adversely affect the tensile strength of wounds [36]. Classes of drugs with their effect on wound healing are tabulated in table 3 . 
Table 3: Examples of drug classes that delay different phases of wound healing

\begin{tabular}{llll}
\hline Class of drugs & Effect on wound healing & References \\
\hline Chemotherapeutic & Detrimental effect on the rapidly divided tissues of healing wounds reduced angiogenesis \\
drugs & reduced tensile strength of wounds negative impact on fibroblast function & [37-40] \\
Antihistamines & Decreased tensile strength of wounds reduced collagen synthesis & [41] \\
Anticoagulants & Inhibits platelet aggregation; inhibits inflammatory mediators, increases risk of wound hematoma \\
NSAID's & $\begin{array}{l}\text { Reduced inflammatory response, excessive wound scarring, antiproliferative effect on blood vessels } \\
\text { Immunosuppressant } \\
\end{array}$ & $\begin{array}{l}\text { Decreased tensile strength in wounds, reduce WBC counts, reducing inflammatory activities and } \\
\text { increasing the risk of wound infection }\end{array}$ \\
\hline
\end{tabular}

\section{Alcoholism and smoking}

Alcohol has been reported to affect all the phases of wound healing with compounded wound healing problems. There is a reduction in pro-inflammatory cytokines and neutrophil function. Alcoholism is associated with a decrease in the rate of wound closure and suppressed angiogenesis, decreased collagen synthesis, and an overall reduction in the tensile strength of the wounds [46]. Smoking causes an overall reduction of tissue oxygenation, reduced collagen synthesis and epithelialization, reduction in lymphocyte and neutrophil functions, and suppressed proliferation of WBC's. These effects result in poor wound healing and an increased risk of opportunistic wound infection [47]. Vitamin C acts as a co-factor for the proline and lysine hydroxylases that stabilize the collagen molecule. According to reports, Smokers have depleted vitamin C levels compared with non-smokers. Smoking cessation can improve the levels of serum collagen with an associated improvement in wound healing and collagen formation $[48,49]$.

\section{Nutrition}

Healing of wounds requires an adequate supply of nutrients. All cellular activities require energy for which diet is the major source. Carbohydrates are the principal source of energy for the body and help sustain the high metabolic activity required for regeneration. Adequate levels of protein are necessary for repair and replacement of tissue. Increased protein intake is particularly important for wounds where there is significant tissue loss requiring the production of large amounts of connective tissue. Protein deficiencies have been associated with poor revascularization, decreased fibroblast proliferation, reduced collagen formation, and immune system deficiencies. Fats provide energy for proliferation. They are the building blocks for the regeneration of epidermal and dermal tissues. Lipids are important for cell membrane synthesis, epidermal phospholipids, inflammatory reactions, and intracellular matrix synthesis. In addition to protein, carbohydrates and lipids, wound healing also requires the presence of micronutrients like Vitamins (A, B complex, C, E, and K) and Minerals (copper, iron, zinc) [9, 50]

\section{Wound dressings}

Wound healing is a complex physiological process and requires a suitable environment that promotes healing. Over the years, several wound healing products have been developed that facilitate one or more phases involved in wound healing. Wound dressing is a material designed to be in contact with the wound and hence differentiated from a bandage that merely holds the dressing in place [51]. An ideal wound dressing would be one which is capable of maintaining the optimum moisture at the wound surface while at the same time being capable of absorbing excess exudates from the wound and hence preventing maceration. The dressing should maintain a sufficient exchange of gases and should be impermeable to bacteria. The other characteristics that are desired would be nontoxic, non-allergic, free from contaminants, not necessitating frequent dressing changes, cost-effective, and comfortable [52].

Technological advancements in wound dressings have seen changes from crude applications of plant herbs, animal fat, and honey to tissue-engineered scaffolds. Some of the reported plant extracts for wound care include Guiera senegalensis, Commelina diffusa, Spathodea campanulata, Trichophyton species, etc. [53]. Honey has been used for thousands of years and is still part of many advanced wound dressings [54]. For several years, traditional wound care products focus on drying the wound site by using absorptive gauzes. Drying resulted in the formation of a crust or scab that usually would fall off as the wound healed. This led to scarring and susceptibility to secondary infection and skin damage in the process of the crust coming off. However, it has now been shown that having a warm moist wound environment achieves more rapid and successful wound healing. It was revealed that the wound is healed twice as fast with an appropriate amount of moisture compared to when dry. Also, the exudate contains much of the growth factors which are necessary for skin regeneration $[2,51,55]$.

\section{Dry dressings}

Traditional wound dressings are regarded as passive devices that intend to protect the wound from further injury. Dressings under this category include natural or synthetic materials like cotton wool, lint, gauze, knitted viscose, and tulle dressings. These dressings absorb the exudate at the wound site and keep it dry. They also prevent the entry of harmful bacteria. Moreover, these materials adhere to the desiccated wound surface inducing trauma on removal $[2,4,51]$.

\section{Moist wound therapy}

The greatest advantage of these dressings is the maintenance of a moist environment at the wound surface. These modern dressings come with other advantages like decreased pain, requiring fewer dressing changes, and reduction in scarring $[2,56]$. Advancements in wound dressings over the years have been outlined in fig. 4 .

\begin{tabular}{lll}
\hline Dry dressing & Moist dressing & \multicolumn{1}{c}{ Advances } \\
- Cotton wool & - Polyurethane films & - Growth factors \\
- Lint & and foams & - Skin substitutes \\
- Gauze & - Alginate & - Hyperbaric oxygen \\
& - Hydrocolloid & - Negative pressure \\
& & wound therapy
\end{tabular}

Fig. 4: Advancements in wounds dressings

Moist wound dressing can fall under one of the following three categories a. Dressings that maintain existing levels of tissue moistureExample: Polyurethane films and hydrocolloids 
b. Dressings that absorb excessive wound exudate-Example: Foam dressings and alginate-based dressings

c. Dressings that add moisture to the tissues-Hydrogel dressing [22]

\section{Moisture maintaining dressings}

\section{Polyurethane film dressings}

These consist of a thin, semipermeable polyurethane film (fig. 5) coated with an adhesive layer enabling the dressing to adhere to intact skin and can stay in place for up to $7 \mathrm{~d}$. The semipermeable nature allows water vapor transmission, which can vary from 300 $\mathrm{g} / \mathrm{m}^{2} / 24 \mathrm{~h}$ to $800 \mathrm{~g} / \mathrm{m}^{2} / 24 \mathrm{~h}$. They protect against bacteria and help in retaining moisture at the wound surface. They do not absorb exudates. Film dressings provide a protective environment, which is impermeable to bacteria and liquids and can stay in place for up to 7 d. They have limited application as a primary dressing wherein they are indicated only for dry and superficial wounds. For heavily exuding wounds, they can be used as a secondary dressing on top of dressing pads or foam dressing $[6,57]$.

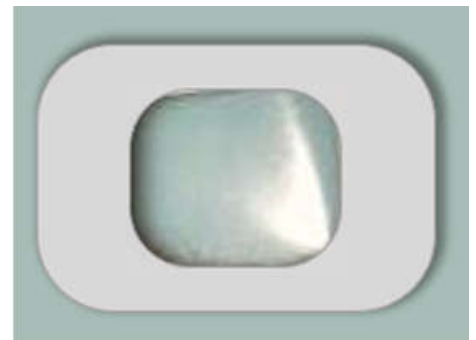

Fig. 5: Polyurethane film dressing [58]

\section{Hydrocolloid dressings}

These are occlusive dressings that are capable of maintaining the natural moisture levels of the regenerated tissues. Similar to film dressings (fig. 6) discussed in the previous section, these also do not have the property of active moisture absorption. The dressing is permeable to air and water vapor but impermeable to fluids and microorganisms $[22,59]$.

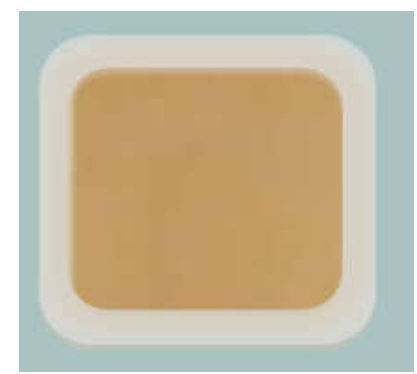

Fig. 6: Hydrocolloid dressing [60]

\section{Moisture absorbing dressings}

In cases where wounds generate moderate to high levels of exudate, an absorbent dressing is needed. Absorbent dressings are those types that have a high capacity for capturing and holding fluid. Included under this category are hydrophilic foams and alginates that are capable of absorbing fluid almost 20 times their weight [59]. Compared to non-absorbent dressings, they require fewer dressing changes and hence enable undisturbed wound healing [22].

\section{Foam dressings}

Foam dressings are generally made from semipermeable polyurethane (fig. 7). They create a moist environment, conducive to wound healing. They are also non-adherent, impermeable to bacteria and other contaminants but permeable to water vapor. They are available as pads, sheets, and cavity dressings [55, 59].

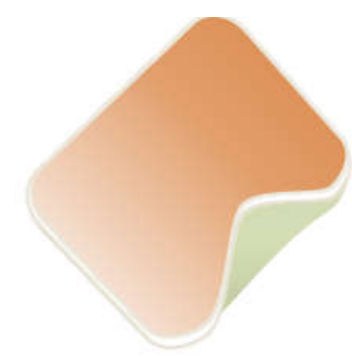

Fig. 7: Polyurethane foam dressing [61]

\section{Calcium alginate dressings}

Alginate dressings are commercially available as pads (fig. 8) ropes or ribbons. These are highly absorbent and get converted to a gel ay absorbing the wound exudates. The dressings can be occlusive to semi-occlusive and suitable for wounds that produce moderate to large amounts of exudates. Using them on wounds with minimum exudates has a chance of drying out the wound bed. Alginates also has haemostatic properties. They have also been suggested to promote healing via a direct modulatory effect on wound macrophages [62-65].

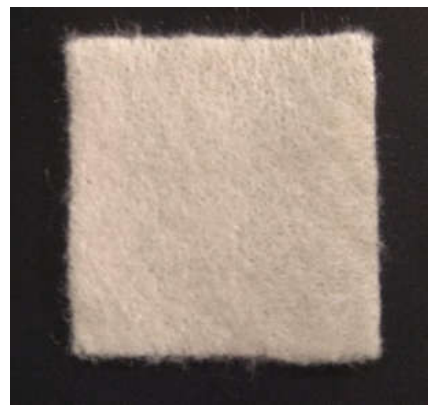

Fig. 8: Calcium alginate dressing [66]

Table 4: Marketed wound dressings

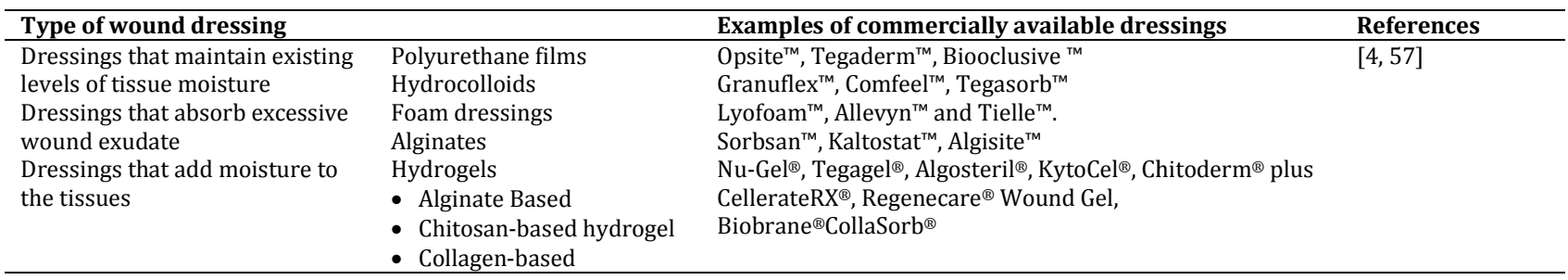




\section{Dressings that add moisture to the wound bed}

\section{Hydrogels}

Hydrogels are vastly hydrophilic macromolecular networks, which are produced by chemical or physical crosslinking of soluble polymers [67]. They contain $90 \%$ water and $10 \%$ natural or synthetic polymers Hydrogel-based wound dressings (fig. 9) are one of the most promising materials in wound care, fulfilling important dressing requirements, including (a) keeping the wound moist whilst absorbing extensive exudate, (b) adhesion-free coverage of sensitive underlying tissue, (c) pain reduction through cooling, (d) permeable nature allowing an exchange of gases and water vapor and (e) they possess tissue-like structure and compatibility [68]. Their main disadvantage is their poor mechanical stability at swollen state, which can be addressed by using composite hydrogel membranes [67].

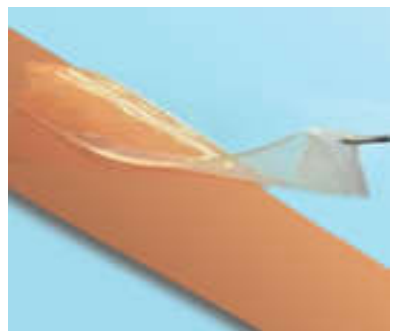

Fig. 9: Hydrogel dressing [69]

\section{Advances in wound dressings}

\section{Growth factors}

Growth factors are endogenous signaling molecules that regulate cellular responses for the wound healing processes of migration, proliferation, and differentiation. Some of the important growth factors involved in wound healing are PGDF, EGF, VEGF, EGF, TGF- $\alpha$ IGF, bFGF, KGF, and TGF- $\beta 1-3$ [70]. Growth factors can be delivered by incorporating them into hydrogels (cellulose, chitosan, or synthetic polymer-based), scaffolds (collagen, chitosan, and hyaluronic acid-based), particulate systems (microparticles, nanoparticles, and liposomes) and miscellaneous systems (integration with charged molecules) [71, 72]

\section{Skin substitutes}

Skin substitutes provide a replacement for the extracellular matrix and accelerate the healing of both acute and chronic wounds. Artificial skin substitutes are often compared with split-thickness skin autografts, which are considered as the 'gold standard' for skin substitutes. Skin substitutes may be made from biological (human or animal origin) or synthetic materials. Temporary skin substitutes provide a physical barrier from bacteria and trauma and can create a moist physiological environment for wound healing. Permanent skin substitutes are meant to replace the components of skin and offer a higher quality of skin replacement. One of the oldest used skin substitutes is amnion, which is the innermost layer of the foetal membrane. It can be prepared in fresh, dried, frozen, freeze-dried irradiated, stabilized, or cryopreserved forms [73]. Patients' epidermal cells are cultured and Cultured Epidermal Autografts (CEA) or artificial skin can be prepared. These can be used on wounds and burns for improved re-epithelization. Dermal substitutes from animal skin and animal collagen have also been used in the management of chronic non-healing wounds [74]. Acellular extracellular matrix scaffold derived from porcine jejunum submucosa fabricated as a dermal substitute has shown evidence of improved tissue regeneration and wound healing. $[75,76]$.

\section{Negative pressure wound therapy (NPWT)}

NPTW is also called vacuum-assisted wound closure. The wound closure is facilitated by the continuous application of subatmospheric pressure to the wound area. Commercially available systems for negative pressure wound therapy (NPWT) include opencell foam dressing put into the wound cavity and the vacuumassisted closure (VAC therapy) device [77] (fig. 10).

NPWT systems consist of an open-pore polyurethane ether foam sponge that is placed over the wound. It is covered by a semiocclusive dressing and then connected to a suction pump [78]. Once in position, the Negative pressure dressing provides a stable environment over the wound surface. This enables the wound to heal even in the mobile patient without shear stresses affecting the wound, which could damage the fragile newly formed tissue. This method of treatment increases local blood flow and reduces edema and bacterial colonization rates. It is thought to promote closure of the wound by promoting the rapid formation of granulation tissue as well as by mechanical effects on the wound. It concurrently provides a moist wound environment and removes excess wound exudates, thus aiding in the creation of the "ideal wound healing environment" [79].

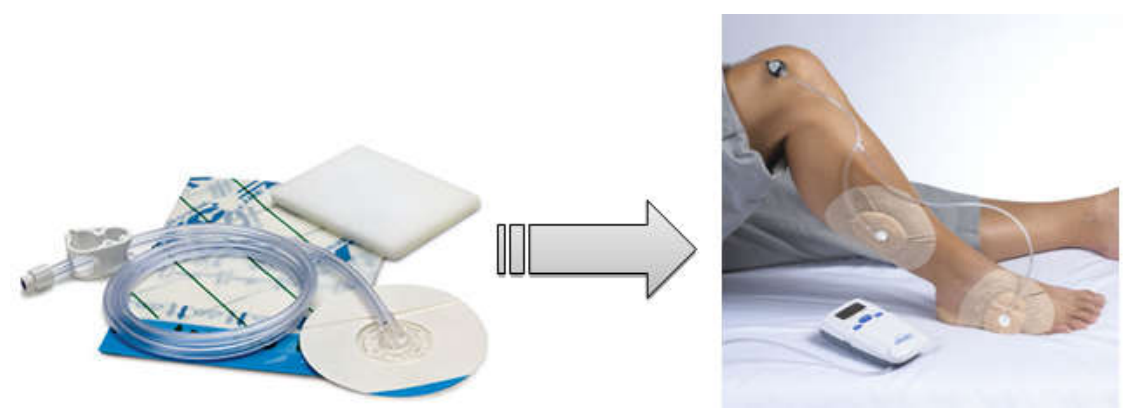

Fig. 10: Negative pressure wound therapy $[80,81]$

\section{Hyperbaric oxygen therapy (HBOT)}

Hyperbaric oxygen therapy (HBOT) is the use of $100 \%$ oxygen at pressures greater than atmospheric pressure. It has been successfully used as adjuvant therapy for the treatment of wounds. HBOT is administered to patients in pressurized chambers (fig. 11) with air or oxygen. The patient breathes oxygen intermittently. Hyperoxia causes vasoconstriction, angiogenesis, fibroblast proliferation, leukocyte oxidative killing, toxin inhibition, and antibiotic synergy $[82,83]$.

\section{Futuristic approaches in wound care}

Almost all of the currently existing wound dressing are passive and do not provide any information regarding the wound bed or the status of healing. Chronic non-healing wounds have been the focus of innovative products intended for wound management. Research in smart systems, devices with sensing, responding, or reporting functions or a combination of these are reported to address many of the challenges associated with wound healing, particularly for chronic wounds [85]. 
pH monitoring wounds dressings help in monitoring the wound status. Extremely high $\mathrm{pH}$ could be a sign of infections in the wound [86-88]. Temperature measurements at the wound site provide information about blood flow and angiogenesis and fibrosis Temperature monitoring wound healing devices $[89,90,95]$ can help in monitoring hypothermia. Dressings with oxygen sensors that can monitor tissue oxygenation can provide valuable data on wound healing $[91,92]$.

In addition to the above, dressings that can monitor moisture levels at the wound site, [93], and wound dress that can deliver drugs or healing factors at a rate and amount required by the healing wound $[94,95]$ are the more recent advances in this field.

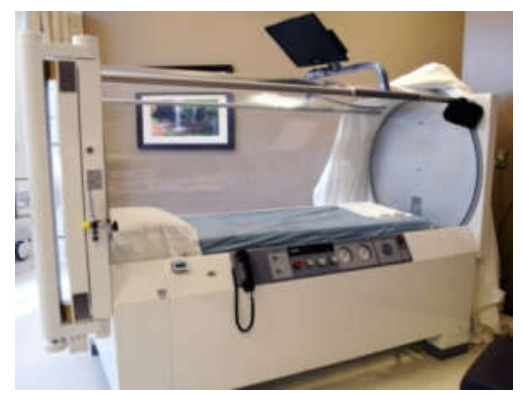

Fig. 11: Hyperbaric oxygen chamber [84]

\section{CONCLUSION}

Wound healing rate and mechanism involve various interlinked and hence all wounds cannot be treated as same. All wounds heal differently. A deep understanding of various physiological and systemic factors is essential for appropriate wound management. With the availability of complex and advanced wound healing devices, it becomes increasingly more important for thorough systematic assessment of the wound and all systemic factors related to wound healing, so that these products can be used effectively with maximum impact. Knowledge about advanced wound healing techniques opens up new avenues in the designing of newer, better, and cost-effective treatment options.

\section{FUNDING}

$\mathrm{Nil}$

\section{AUTHORS CONTRIBUTIONS}

All the authors have contributed equally.

\section{CONFLICT OF INTERESTS}

Declared none

\section{REFERENCES}

1. Takeo M, Lee $W$, Ito $M$. Wound healing and skin regeneration CSH Perspect Med 2015;5:a023267.

2. Kim GH, Kang YM, Kang KN, Kim DY, Kim H. Wound dressings for wound healing and drug delivery. Tissue Eng Regen Med 2011;8:1-7.

3. Rossi S, Faccendini A, Bonferoni M, Ferrari F, Sandri G, Del Fante C, et al. "Sponge-like" dressings based on biopolymers for the delivery of platelet lysate to skin chronic wounds. Int J Pharm 2013;440:207-15.

4. Boateng J, Matthews K, Stevens H, Eccleston G. Wound healing dressings and drug delivery systems: a review. J Pharm Sci 2008;97:2892-923.

5. Kapoor M, Clarkson A, Sutherland B, Appleton I. The role of antioxidants in models of inflammation: emphasis on l-arginine and arachidonic acid metabolism. Inflammopharmacol 2005;12:505-19.

6. Hanna J, Giacopelli J. A review of wound healing and wound dressing products. J Foot Ankle Surg 1997;36:2-14.
7. Velnar T, Bailey T, Smrkolj V. The wound healing process: an overview of the cellular and molecular mechanisms. J Int Med Res 2009;37:1528-42.

8. Thomas Hess C. Checklist for factors affecting wound healing. Adv Skin Wound Care 2011;24:192.

9. Guo S, Di Pietro L. Factors affecting wound healing. J Dent Res 2010;89:219-29.

10. Howard M Kimmel, Anthony Grant, James Ditata. The presence of oxygen in wound healing. Wounds 2016;28:264-70.

11. Sen C. Wound healing essentials: let there be oxygen. Wound Repair Regen 2009;17:1-18.

12. Rodriguez P, Felix F, Woodley D, Shim E. The role of oxygen in wound healing: a review of the literature. Dermatol Surg 2008;34:1159-69.

13. Schreml S, Szeimies R, Prantl L, Karrer S, Landthaler M, Babilas P. Oxygen in acute and chronic wound healing. Br J Dermatol 2010;163:257-68.

14. Edwards R, Harding K. Bacteria and wound healing. Curr Opin Infect Dis 2004;17:91-6.

15. Negut I, Grumezescu V, Grumezescu A. Treatment strategies for infected wounds. Molecules 2018:23:2392.

16. Bowler P, Duerden B, Armstrong D. Wound microbiology and associated approaches to wound management. Clin Microbiol Rev 2001;14:244-69.

17. Ki V, Rotstein C. Bacterial skin and soft tissue infections in adults: a review of their epidemiology, pathogenesis, diagnosis, treatment and site of care. Can J Infect Dis Med 2008;19:173-84.

18. Rodgers A, Lynne W. Maceration and its effect on periwound margins. Diabetic Foot. 2003;6:S2+.

19. Haryanto H, Arisandi D, Suriadi S, Imran I, Ogai K, Sanada H, et al. Relationship between maceration and wound healing on diabetic foot ulcers in Indonesia: a prospective study. Int Wound J 2016;14:516-22.

20. Grey J, Enoch S, Harding K. Wound assessment. Br Med J 2006;332:285-8.

21. Demidova Rice T, Hamblin M, Herman I. Acute and impaired wound healing. Adv Skin Wound Care 2012;25:304-14.

22. Ovington L. Advances in wound dressings. Clin Dermatol 2007;25:33-8.

23. Atiyeh B, Ioannovich J, Al-Amm C, El-Musa K. Management of acute and chronic open wounds: the importance of moist environment in optimal wound healing. Curr Pharm Biotechnol 2002;3:179-95.

24. Jones PL, Millman A. Wound healing and the aged patient. Nurs Clin N Am 1990 Mar; 25:263-77

25. Sgonc R, Gruber J. Age-related aspects of cutaneous wound healing: a mini-review. Gerontology 2013;59:159-64.

26. Gerstein A, Phillips T, Rogers G, Gilchrest B. Wound healing and aging. Dermatol Clin 1993;11:749-57.

27. Rojas I, Padgett D, Sheridan J, Marucha P. Stress-induced susceptibility to bacterial infection during cutaneous wound healing. Brain Behav Immun 2002;16:74-84.

28. Christian L, Graham J, Padgett D, Glaser R, Kiecolt Glaser J Stress and wound healing. Neuroimmunomodulation 2006;13:337-46.

29. Lucas VS. Psychological stress and wound healing in humans: what we know. Wounds-a Compendium Clin Res Practice 2011;23:76-83

30. Wynn M, Holloway S. The impact of psychological stress on wound healing: a theoretical and clinical perspective. Wounds UK; 2019. p. 15.

31. Gouin J, Kiecolt Glaser J. The impact of psychological stress on wound healing: methods and mechanisms. Immunol Allergy Clin 2011;31:81-93.

32. Tandara A, Mustoe T. Oxygen in wound healing? More than a Nutrient. World J Surg 2004;28:294-300.

33. Rosenberg CS. Wound healing in the patient with diabetes mellitus. Nurs Clin N Am 1990;25:247-61.

34. Pence BD, Woods JA. Exercise, obesity, and cutaneous wound healing: evidence from rodent and human studies. Adv Wound Care 2014;1:71-9.

35. Wagner IJ, Szpalski C, Allen Jr RJ, Davidson EH, Canizares O, Saadeh PB, Warren SM. Obesity impairs wound closure through a vasculogenic mechanism. Wound Repair Regen 2012;20:512-22. 
36. Wigston CH, Hassan SH, Turvey SU, Bosanquet DA, Richards AL Holloway SA, et al. Impact of medications and lifestyle factors on wound healing: a pilot study. Wounds UK 2013;9:22-8

37. Payne WG, Naidu DK, Wheeler CK, Barkoe D, Mentis M, Salas RE, et al. Wound healing in patients with cancer. Eplasty 2008;8:e9.

38. Tershakowec M, Ferguson MK. The effect of antineoplastic agents on wound healing. Plast Reconstr Surg 1982;70:785

39. Cohen SC, Gabelnick HL, Johnson RK, Goldin A. Effects of antineoplastic agents on wound healing in mice. Surg 1975;78:238-44.

40. Kaiser GA, Herter FP, Malm JR, Demetz A, Campione MP. Effects of chemotherapeutic agents administered by isolated perfusion upon wound healing. Surg 1961;49:745-50.

41. Bairy KL, Rao CM, Ramesh KV, Kulkarni DR. Effects of antihistamines on wound healing. Indian J Exp Biol 1991;29:398-9.

42. Drugs that delay wound healing. Prescrire Int 2013;22:94-8.

43. Anderson K, Hamm RL. Factors that impair wound healing. J Am Coll Clin Wound 2012;4:84-91.

44. Bootun R. Effects of immunosuppressive therapy on wound healing. Int Wound J 2013;10:98-104.

45. Allegranzi B, Bischoff P, De Jonge S, Kubilay NZ, Zayed B, Gomes $\mathrm{SM}$, et al. New WHO recommendations on preoperative measures for surgical site infection prevention: an evidencebased global perspective. Lancet Infect Dis 2016;16:e276-87.

46. Jung MK, Callaci JJ, Lauing KL, Otis JS, Radek KA, Jones MK, et al. Alcohol exposure and mechanisms of tissue injury and repair. Alcohol Clin Exp Res 2011;35:392-9.

47. Mc Daniel JC, Browning KK. Smoking, chronic wound healing, and implications for evidence-based practice. J Wound Ostomy Continence Nursing 2014;41:415.

48. Pullar JM, Carr AC, Vissers $M$. The roles of vitamin $C$ in skin health. Nutrients 2017;9:866.

49. Schectman G, Byrd JC, Gruchow HW. The influence of smoking on vitamin C status in adults. Am J Public Health 1989;79:158-62.

50. Williams JZ, Barbul A. Nutrition and wound healing. Surg Clin N Am 2003;83:571-96.

51. Dhivya S, Padma VV, Santhini E. Wound dressings-a review. Bio Medicine 2015;5:22.

52. Jones V, Grey JE, Harding KG. Wound dressings. Br Med J 2006;332:777-80.

53. Boateng JS, Matthews KH, Stevens HN, Eccleston GM. Wound healing dressings and drug delivery systems: a review. J Pharm Sci 2008;97:2892-923.

54. Shah JB. The history of wound care. J Am Coll Clin Wound Spec 2011;3:65-6.

55. Sarabahi S. Recent advances in topical wound care. Indian J Plast Surg 2012;45:379-87.

56. Baranoski S, Ayello EA. Wound dressings: an evolving art and science. Adv Skin Wound Care 2012;25:87-92.

57. Abdelrahman T, Newton H. Wound dressings: principles and practice. Surg (Oxford) 2011;29:491-5.

58. Swezey L. The continuum of wound dressings-semipermeable film dressings. In: Woundeducators.com blog; 2015. Available from: https://woundeducators.com/semipermeable-filmdressings [Last accessed on 13 Jul 2020]

59. Murphy PS, Evans GR. Advances in wound healing: a review of current wound healing products. Plast Sur Int 2012. DOI:10.1155/2012/190436

60. acelity.com [Internet] Nu-Derm hydrocolloid wound dressing Available from: https://www.acelity.com/healthcareprofessionals/global-product-catalog/catalog/nu-dermhydrocolloid-wound-dressing. [Last accessed on 13 Jul 2010]

61. bifixmed.com medical poly surgical foam dressing; Available from: http://www.bifixmed.com/product/medical-polysurgical-foam-dressing. [Last accessed on 13 Jul 2020]

62. Cooper C. Fundamentals of hand therapy-e-book: clinical reasoning and treatment guidelines for common diagnoses of the upper extremity. Elsevier Health Sciences; 2014.

63. Leveriza-Oh M, Phillips T. Dressings and postoperative care Lower Extremity Soft Tissue Cutaneous Plastic Surgery 2012:471-88. DOI:10.1016/B978-0-323-02752-6.50013-4

64. Agarwal A, McAnulty JF, Schurr MJ, Murphy CJ, Abbott NL. Polymeric materials for chronic wound and burn dressings. In:
Advanced Wound Repair Therapies. Woodhead Publishing; 2011. p. 186-208.

65. Aderibigbe BA, Buyana B. Alginate in wound dressings. Pharmaceutics 2018;10:42.

66. buyemp.com. Dynarex dynaginate calcium alginate dressing, Available from https://www.buyemp.com/product/dynarexdynaginate-calcium-alginate-dressing. [Last accessed on $13 \mathrm{Jul}$ 2020].

67. Kamoun EA, Kenawy ER, Chen X. A review on polymeric hydrogel membranes for wound dressing applications: PVAbased hydrogel dressings. J Adv Res 2017;8:217-33.

68. Koehler J, Brandl FP, Goepferich AM. Hydrogel wound dressings for bioactive treatment of acute and chronic wounds. Eur Polym J 2018;100:1-1.

69. kikgel.com.pl [Internet] sterile hydrogel wound dressing for moist wound management. Available from: https://kikgel.com.pl/produkty/neoheal. [Last accessed on 13 Jul 2020]

70. Braund R, Hook S, Medlicott NJ. The role of topical growth factors in chronic wounds. Curr Drug Delivery 2007;4:195-204.

71. Park JW, Hwang SR, Yoon IS. Advanced growth factor delivery systems in wound management and skin regeneration. Molecules 2017;22:1259.

72. buyemp.com [Internet] Dynarex dynaginate calcium alginate dressing. Available from: https://www.buyemp.com/ product/dynarex-dynaginate-calcium-alginate-dressing. [Last accessed on 13 Jul 2020].

73. Briquez PS, Hubbell JA, Martino MM. Extracellular matrixinspired growth factor delivery systems for skin wound healing. Adv Wound Care 2015;4:479-89.

74. Zelen CM, Gould L, Serena TE, Carter MJ, Keller J, Li WW. A prospective, randomised, controlled, multi-center comparative effectiveness study of healing using dehydrated human amnion/chorion membrane allograft, bioengineered skin substitute or standard of care for treatment of chronic lower extremity diabetic ulcers. Int Wound J 2015;12:724-32.

75. Mian M, Beghe F, Mian E. Collagen as a pharmacological approach in wound healing. Int J Tissue React 1992;14:1-9.

76. Guest JF, Weidlich D, Singh H, La Fontaine J, Garrett A, Abularrage CJ, et al. Cost-effectiveness of using adjunctive porcine small intestine submucosa tri-layer matrix compared with standard care in managing diabetic foot ulcers in the US. J Wound Care 2017;26:S12-24.

77. Dai C, Shih S, Khachemoune A. Skin substitutes for acute and chronic wound healing: an updated review. J Dermatol Treat 2018;28:1-33.

78. Chiummariello S, Guarro G, Pica A, Alfano C. Evaluation of negative pressure vacuum-assisted system in acute and chronic wounds closure. Our Exp 2012;33:358-62.

79. Putnis S, Khan WS, Wong JM. Suppl 1: Negative pressure wound therapy-a review of its uses in orthopaedic trauma. Open Orthop J 2014;8:142.

80. acelity.com V. A. C. White foam dressing kits. Available from: https://www.acelity.com/healthcare-professionals/globalproductcatalog/catalog/vac-therapy-whitefoam-dressings. [Last accessed on 13 Jul 2020]

81. omegamedicalsystems.com. Negative pressure wound treatment system. Available from: http://www.omegamedicalsystems.com/html/negative_pressu re_wound_therap.html. [Last accessed on 13 Jul 2020]

82. Jones SM, Banwell PE, Shakespeare PG. Advances in wound healing: topical negative pressure therapy. Postgrad Med J 2005;81:353-7.

83. Bhutani S, Vishwanath G. Hyperbaric oxygen and wound healing. Indian J Plast Surg 2012;45:316-24.

84. Dick Clarke. An evidence-based approach to hyperbaric wound healing; 1998.

85. Derakhshandeh H, Kashaf SS, Aghabaglou F, Ghanavati IO Tamayol A. Smart bandages: the future of wound care. Trends Biotechnol 2018;36:1259-74.

86. Tamayol A, Akbari M, Zilberman Y, Comotto M, Lesha E, Serex L, et al. Flexible pH-sensing hydrogel fibers for epidermal applications. Adv Healthc Mater 2016;5:711-9.

87. Kassal P, Kim J, Kumar R, De Araujo WR, Steinberg IM, Steinberg MD, et al. Smart bandage with wireless connectivity 
for uric acid biosensing as an indicator of wound status. Electrochem Commun 2015;56:6-10.

88. Panzarasa G, Osypova A, Toncelli C, Buhmann MT, Rottmar M, Ren $\mathrm{Q}$, et al. The pyranine-benzalkonium ion pair: a promising fluorescent system for the ratiometric detection of wound $\mathrm{pH}$. Sensors Actuators B: Chem 2017;249:156-60.

89. Hattori Y, Falgout L, Lee W, Jung SY, Poon E, Lee JW, et al Multifunctional skin-like electronics for quantitative, clinical monitoring of cutaneous wound healing. Adv Healthc Mater 2014;3:1597-607.

90. Salvo P, Calisi N, Melai B, Dini V, Paoletti C, Lomonaco T, et al Temperature-and pH-sensitive wearable materials for monitoring foot ulcers. Int J Nanomed 2017;12:949.

91. Mostafalu P, Lenk W, Dokmeci MR, Ziaie B, Khademhosseini A Sonkusale SR. Wireless flexible smart bandage for continuous monitoring of wound oxygenation. IEEE Transactions Biomed Circuits Systems 2015;9:670-7.

92. Li Z, Roussakis E, Koolen PG, Ibrahim AM, Kim K, Rose LF, et al. Non-invasive transdermal two-dimensional mapping of cutaneous oxygenation with a rapid-drying liquid bandage. Biomed Opt Express 2014;5:3748-64.

93. Milne SD, Seoudi I, Al Hamad H, Talal TK, Anoop AA, Allahverdi $\mathrm{N}$, et al. A wearable wound moisture sensor as an indicator for wound dressing change: an observational study of wound moisture and status. Int Wound J 2016;13:1309-14.

94. Bagherifard S, Tamayol A, Mostafalu P, Akbari M, Comotto M, Annabi N, et al. Dermal patch with integrated flexible heater for on demand drug delivery. Adv Healthc Mater 2016;5:175-84.

95. Mostafalu P, Kiaee G, Giatsidis G, Khalilpour A, Nabavinia M, Dokmeci MR, et al. A textile dressing for temporal and dosage controlled drug delivery. Adv Funct Mater 201;27:1702399. 